\title{
A Matemática, a Arte, os surdos e a EJA - Educação de Jovens e Adultos - uma intervenção interdisciplinar
}

Rúbia Carla da Silva

Eloiza Aparecida Ávila de Matos

\section{Resumo}

Este artigo apresenta os resultados de uma pesquisa de mestrado quanto ao desenvolvimento da disciplina de Libras em um curso de Licenciatura em Matemática de uma IES da cidade de Ponta Grossa - PR, a partir de uma intervenção na EJA quanto ao atendimento de alunos surdos inclusos. Teve como objetivo geral avaliar a metodologia de ensino da Libras aplicada em curso de Licenciatura em Matemática. A metodologia foi organizada em três momentos: levantamento do referencial teórico; desenvolvimento da disciplina de Libras em uma turma do curso de Licenciatura em Matemática; e a construção do objeto de aprendizagem em uma turma de EJA. Após a análise e interpretação dos dados, obtiveram-se resultados satisfatórios, porém evidenciando as dificuldades encontradas ao longo do processo, que deixaram evidentes a necessidade de novas estratégias para o ensino da Libras na formação de professores, tornando esta pesquisa fundamental para esse fim.

Palavras-chave: ensino de matemática, formação de professor, Libras.

\section{Abstract \\ Mathematics, Art, the deaf and the EJA - Youth and Adult Education - an interdisciplinary intervention}

This article presents the results of a Master thesis on the development of Brazilian Sign Language (BSL) of discipline in a Mathematics Degree program at University of Ponta Grossa City (PR), from an intervention in adult education as service included deaf students. Aimed to assess the BSL teaching methodology applied in the Bachelor's Degree in Mathematics. The methodology was organized in three stages: a survey of the theoretical framework; development of BSL of discipline in a class of Bachelor's Degree in Mathematics; and the construction of the learning object in a class of adult education. After the analysis and interpretation of the data yielded satisfactory results, but showing the difficulties encountered along the way, who left evident the need for new strategies for teaching BSL in teacher education, making this fundamental research for this purpose.

Keywords: mathematics education, teacher training, Brazilian Sign Language. 


\section{Introdução}

Nos cursos de formação de professores - Licenciaturas - além dos diversos conhecimentos inerentes a cada área do saber, deve-se também promover a competência para o atendimento ao alunado com NEE - Necessidades Educacionais Especiais. Neste contexto, a especificidade dos alunos é a surdez, os quais têm uma diferença linguística marcada por uma língua da modalidade visual-gestual (e não oral-auditiva).

De caráter interdisciplinar, aplicada e qualitativo-explicativa, a pesquisa de mestrado pertencente ao PPGECT - Programa de Pós-Graduação em Ensino de Ciência e Tecnologia - da UTFPR - Universidade Tecnológica Federal do Paraná, unidade Ponta Grossa, teve como objetivo geral avaliar o ensino da Libras aplicado em curso de Licenciatura em Matemática. Para tanto, a metodologia foi organizada em momentos distintos.

O primeiro, para o levantamento e leitura do referencial teórico relacionado à educação dos surdos, legislação, aspectos linguísticos da Libras, TICs, ensino de língua estrangeira, diferentes formas de linguagens e sobre a formação de professores. O segundo momento foi durante a execução da disciplina de Libras, no segundo semestre de 2013, com acadêmicos do terceiro ano do curso de Licenciatura em Matemática, de uma IES da cidade de Ponta Grossa. E o terceiro momento se constituiu da organização e aplicabilidade do objeto de aprendizagem, por meio de uma Unidade Didática com abordagem matemática nas artes visuais, especificamente na Op Art. Essa intervenção ocorreu em uma turma de EJA - Educação de Jovens e Adultos, em que havia três alunos surdos inclusos, no intuito de se verificar a contribuição efetiva da disciplina de Libras para a formação dos futuros professores de Matemática.

Deve-se considerar que para o efetivo processo comunicativo entre professor ouvinte e aluno surdo não basta a apropriação apenas linguística da Libras, por parte do professor, mas o entendimento sobre aspectos culturais, legislação vigente e concepções educacionais para surdos, bem como outros fatores fundamentais para o êxito do trabalho docente.

\section{Referencial Teórico}

O ato de fala ou ato de sinalização é um ato social complexo, que extrapola a competência linguística, tecendo uma rede de dependência global, envolta em um emaranhado cultural (principalmente quando se trata de interlocutores com domínios de línguas diferentes). Essa variação cultural distinta apresenta aspectos rotineiros, rituais e os atos de linguagem que compõem todo o discurso e sua progressão, bem como as regras de conversação e pontuação, notados na oralidade, escrita ou na sinalização (MARTINEZ, 2009).

Diante disso, considera-se que há uma infinidade de linguagens, em amplo sentido do termo, se se relacionar quadros de pintura, peças musicais, modas indumentárias, jogos 
desportivos, relações de parentesco entre outros exemplos, como representações das propriedades sociais específicas, capazes de expressar sob diferentes maneiras o mesmo significado pretendido. Isto posto, as linguagens passam a ter uma função controladora comportamental em que um membro exerce sobre o outro, pertencentes a um grupo social, sem se ter consciência da complexidade comunicacional (LOPES, 2007).

Desde os primeiros manifestos de comunicação dos seres humanos, o homem faz associações para representar a realidade que o cerca, ou as experiências vivenciadas por ele, em um espaço de tempo. Essas associações não diziam respeito unicamente as suas ações de sobrevivência, mas a uma forma de representar todo e qualquer elemento. Assim, surgem as primeiras formas de supostas 'contagens' desenvolvidas pelo homem. Para cada elemento real era determinada uma forma de representação, podendo ser um ruído, ou o uso de um outro elemento menor como pedras, gravetos ou frutas, por exemplo (SANTOS et al, 2010).

As associações numéricas (quantificação) que anteriormente eram representadas pela reunião de elementos menores, passaram a ser indicadas pela criação de símbolos. Os sumérios e os egípcios deixaram registros dessas simbologias, sendo completamente diferentes uma da outra. Também os gregos desenvolveram um sistema de símbolos para representação associativa à quantificação de elementos. Já os hebreus e árabes utilizavam um sistema alfanumérico que se confundia com a escrita, não permitindo a diferenciação entre registro escrito e representação numérica (IFRAH, 1997).

Outra representação numérica largamente conhecida é o sistema de numeração romano, similar ao sistema grego. Neste era possível utilizar o princípio da adição, multiplicação e subtração, mas quanto mais ordens decimais eram utilizadas, maior era a complexidade de representação. Atualmente é utilizado apenas para representar a numeração dos séculos e os incisos na legislação. Os maias, com alto grau de desenvolvimento, utilizavam apenas dois símbolos que combinados e repetidos de diversas maneiras representavam valores diferentes, e um terceiro símbolo para representar um valor nulo (zero). O mais conhecido sistema de numeração é o indo-arábico, idealizado pelos hindus, mas divulgado pelos árabes. Os traços utilizados para a representação numérica era muito distinto do atual, que passou a ser a versão latina dos dez algarismos utilizados nos cálculos matemáticos (SANTOS et al, 2010).

Porém o surgimento dos nomes dos números está diretamente relacionado aos gestos e fala humanos. Os primeiros registros encontrados sobre isso, relatam das tribos do nordeste da ilha de Nova Guiné, localizada no sudoeste do Oceano Pacífico, que 'nomeavam' as representações quantitativas (símbolos) com os nomes de partes do corpo que eram utilizados para indicar certa quantidade. Logo, o nome do dedo mínimo servia para representar tanto o número 1 quanto o número 22, pois podia se considerar o dedo da mão direita como o da esquerda. Eram utilizados os nomes e as partes correspondentes do corpo como os dedos das mãos e dos pés, ombros, cotovelos, joelhos, pulsos, nádegas, manúbrio-esternal (região do osso 
esterno), olhos, orelhas e mamilos para a representação numérica gestual e oral (IFRAH, 1997; SANTOS et al, 2010).

Isso evidencia que para diferentes grupos sociais, as orientações corporais como representação numérica, não representavam um 'número' propriamente dito na concepção atual do termo, mas gestos ou partes do corpo combinados em gestos que representavam uma associação entre unidade (quantidade ' $x$ ') e imagem (parte do corpo), caracterizando certa quantidade de elementos reais. De igual forma para as representações simbólicas (sinais gráficos de qualquer espécie), escritas e orais. Portanto, a manifestação gestual precedeu a expressão oral dos números, igualmente ocorrido com os signos-linguísticos orais, para que posteriormente houvesse a criação de sinais gráficos representativos das letras e dos algarismos.

Dentre as necessidades humanas em um grupo social, a de registrar visualmente seu pensamento, tornando-o 'eterno', fez com que a escrita fosse considerada o melhor meio de comunicação e expressão durável, conservando permanentemente as falas ditas em um determinado lugar e época (IFRAH, 1997; SAUSSURE, 1995).

O sistema de signos escritos, idealizada pelo Sumérios há mais de cinco mil anos, tornou possível o reavivar do pensamento. Os registros em forma de cunhas inicialmente em argilas (depois em pedras, folhas, couros ou papéis) permitiram que essa nova linguagem disciplinasse o pensamento, sendo necessária sua organização mental, para poder transcrevê-lo em diferentes meios. O que permitiu não só o acesso ao mundo das ideias, mas a sua perpetuação no tempo e no espaço (IFRAH, 1997).

Com a evolução da humanidade por meio do contato entre sociedades distintas, seja por guerra (disputa de território) ou por comercialização de iguarias, a invenção do alfabeto serviu para escrever (registrar) toda e qualquer palavra oral, mediante um agrupamento de sinais, chamados 'letras', que combinados representavam todos os sons produzidos pelos falantes.

Tal invenção, criada pelos fenícios por volta do século IX A.C., promovia uma forma de abreviação das complexas escritas egípcias (hieróglifos) ou assírio-babilônicas (herdadas dos Sumérios) usadas no Oriente, como forma de manter o controle para os registros comerciais, inventários e outras formas de contabilidade, uma vez que a escrita egípcia ou a cuneiforme dificultavam tal feito. Esse alfabeto fenício serviu de base para a criação do alfabeto grego (primeiro a ter vogais), que por sua vez contribuiu para os alfabetos itálicos osco, umbro e etrusco, e ao latim (origem da Língua Portuguesa) (IFRAH, 1997; SANTOS et al, 2010).

Também o surgimento dos números seguia a ordenação das letras, sendo pronunciadas em sequência como representação quantitativa. As tabuletas de Heliastes servem como exemplo. Diferentes povos da antiguidade idealizaram a notação numérica mediante as letras do alfabeto fenício, copiando a ordenação fixa das letras. Percebe-se isso também na enumeração de datas, parágrafos e versos do Antigo Testamento, em hebraico, cujo uso ainda remonta as letras do 
alfabeto. Assim, organizou-se a numeração colocando as letras hebraicas na mesma ordem que as fenícias, considerando as nove primeiras aos nove primeiros números, as nove letras seguintes às nove dezenas e as quatro últimas letras às quatro centenas. Portanto, ao escrever um número maior bastava justapor letras que indicavam as ordens das unidades de maneira consecutiva (IFRAH,1997).

Para os gregos a organização numérica se deu igualmente pela organização fenícia e hebraica, dando um valor para cada letra do alfabeto, seguindo a ordenação fixa das letras. Evidencia-se, portanto, que tanto a representação gráfica de letras quanto a de algarismos, foi se constituindo de maneira aleatória ou arbitrária, passando por transformações (evolução) lentas (MORAES et al, 2008).

Todo e qualquer sistema de escrita necessita de um conjunto básico de 'símbolos' previamente definidos; um conjunto normativo (regras de uso) convencional compartilhado por um grupo social; e uma linguagem oral ou sinalizada, representativa dos elementos reais, representada pela simbologia criada por esse mesmo grupo social, ou herdada de outro grupo.

De igual forma, surgiu em 1974, por Valerie Sutton, a escrita das línguas de sinais (ELS). Um sistema de registro que utiliza símbolos visuais que representam as diferentes formas que as mãos assumem durante a constituição dos termos sinalizados. É utilizado para escrever qualquer língua de sinais, igualmente como outros alfabetos que são utilizados por diferentes línguas orais em suas representações gráficas, como o alfabeto romano (latino) (SUTTON, 2009).

O 'Signwriting', como é chamado, é um sistema de escrita a partir de características gráficas e esquemáticas para representar a comunicação visuogestual das línguas de sinais, diferenciandose dos demais sistemas de escrita formal inventados pelo homem no transcorrer da história. De igual forma que os ouvintes utilizam o alfabeto para registro escrito, os surdos necessitam registrar sua língua sinalizada, e isso começou a ser possível por meio desse sistema. Aqui no Brasil, foi a partir de 1996 que foram direcionados olhares a esse sistema de escrita, despertando surdos e pesquisadores linguistas ouvintes ao conhecimento e entendimento dos sinais gráficos utilizados para representar não apenas as letras do alfabeto de outra língua, mas para representar toda e qualquer configuração de mão utilizada na comunicação sinalizada (STUMPF, s/d).

As línguas surgem como resultado de um conjunto de elementos relacionados de maneira particular em grupos linguísticos distintos, que se constitui em um fator determinante no desenvolvimento da identidade e do sentimento de pertinência social. Como Bakhtin (1990 apud SLOMSKI, 2011) afirma, a língua é definida como um sistema semiótico criado e produzido no contexto social e dialógico. Tem-se, por conseguinte, que a linguagem é entendida como forma de interação social, por meio dos discursos resultantes da interação humana, em que é manifestada pelo uso das línguas. Passa a ter sentido quando envolve compreensão e significação, já que o desenvolvimento intelectual se organiza e se amplia pela própria linguagem. 
As línguas de sinais são esses sistemas semióticos criados espontaneamente (arbitrariamente) por um grupo social - os surdos - e produzidos no plano visuoespacial, contendo as propriedades universais que caracterizam a linguagem humana. É o símbolo da identidade e um dos artefatos culturais dos surdos. As pessoas 'não-surdas' (ouvintes) encontram muita dificuldade em admitir esses processos culturais específicos surdos, resultando em uma continuidade no tratamento aos surdos como um grupo deficiente ou incapaz (SLOMSKI, 2011).

Sendo assim, assume-se que há uma cultura surda, e se subentende que há também uma segregação entre os surdos e ouvintes, uma divisão social. É através dessa constituição heterogênea que são observadas as representações que impõem eficácia nos princípios dessa divisão. A defesa de uma cultura surda evidencia os modos de reprodução dessa desigualdade e o termo cultura passa a ser uma maneira de legitimar essa desigualdade na tentativa de manter uma suposta homogeneidade (SANTANA, 2007).

A percepção dos ouvintes, desde o final do século XIX, quanto à importância da língua de sinais como um dos aspectos identitários surdos, contribuiu historicamente para que houvesse uma verdadeira violência contra a comunidade surda, quando da proibição de uso das línguas de sinais em instituições educacionais. Houve a partir de então um 'silenciamento' da cultura surda, pois os surdos tinham as suas mãos amarradas, a fim de que não utilizassem a língua natural, a qual embasa o mundo cognitivo dos surdos (SILVA, 2009).

A afirmação das identidades e da diferença cultural dos surdos traduz um desejo pela garantia do acesso aos bens sociais enquanto direito. As identidades surdas parecem ser constituídas pela carência, privação, e limitação, impostas pela surdez, e não pelas línguas de sinais. Mas há uma língua que permite a possibilidade de se constituir no mundo como 'falante', isto é, sua subjetividade é formada por essa linguagem diferenciada em (re)formulação nas suas relações sociais.

A identidade de um sujeito relaciona-se às práticas sociais, não a uma língua em especial. São as interações diversas, e não apenas as comunicativas, no transcorrer de sua vida que possibilitam reconhecer a complexidade das discussões sobre identidades no âmbito da surdez, em que se busca estabelecer uma 'norma' teórica relacionada a uma identidade específica, exigindo que haja equivalência nas análises correlacionadas a essa suposta norma. Isto quer dizer que haveria uma norma de identidade - a surda, e uma norma cultural equivalente - a cultura surda (SILVA, 2009).

Diante desses esclarecimentos, pode-se depreender que para haver comunicação em uma língua estrangeira, ou mesmo para aprendê-la, não se pode limitar exclusivamente ao sistema linguístico de uma língua. Portanto, o ensino da Matemática para alunos surdos por meio da língua de sinais, requer do profissional não apenas o conhecimento da linguagem matemática e da sinalizada, mas as questões histórico-culturais que permeiam esses indivíduos, o processo 
educacional por eles vivenciado ao longo de suas trajetórias, bem como o conhecimento dos recursos tecnológicos disponíveis para melhor interação e permissão de acesso a assuntos organizados em língua de sinais, somente possíveis em registros midiáticos visuais.

\section{A Disciplina Libras}

Desde que a utilização da Libras nas salas de aula passou a ser praticada, nos fins da década de 80 e início da década de 90, os educadores de um modo geral buscam ter maior conhecimento dessa língua, para que sua atuação seja mais adequada e cumpra com seu verdadeiro papel. Vários foram os recursos utilizados para esta capacitação: oficinas, minicursos, palestras, seminários. Atualmente, tem-se a obrigatoriedade da disciplina de Libras na grade curricular dos Cursos de Fonoaudiologia e cursos de Licenciaturas, como parte da formação do educador e em outros cursos bacharelados pode constar como disciplina optativa, por meio da Lei 10.436/2002 e do Decreto 5.626/2005.

Embora a legislação oriente sobre mecanismos de acessibilidade às pessoas com NEE, o que se tem alcançado é o mínimo em relação ao necessário. Tavares e Carvalho (2010) argumentam que há um distanciamento enorme no que diz respeito aos documentos (leis) e a sua implementação. $\mathrm{Na}$ área da surdez isso fica evidente, a acessibilidade prevista em lei garante a presença de intérprete em sala de aula, adaptação curricular e avaliativa, materiais informativos aos professores sobre as especificidades do surdo atendido, entre outros aspectos.

Mas, na prática, o aluno surdo ainda fica mais excluído que incluído em sala de aula regular, a começar pela capacitação do próprio intérprete. Como exemplo, um intérprete formado em Letras, atuando em uma aula de Física. Por outro lado, os professores, na grande maioria, não tem um conhecimento mínimo da Libras, e com uma carga horária exaustiva de trabalho não conseguem buscar uma formação continuada na área. Dessa forma, as barreiras comunicativas e o desconhecimento das NEE presentes no meio educacional, geram dificuldades e equívocos relacionados ao atendimento de alunos surdos (ALMEIDA; VITALIANO, 2012).

A disciplina de Libras, uma vez obrigatória, não quer dizer que os professores tenham que ministrar suas aulas em Libras, mesmo porque nenhuma carga horária apresentada nos cursos de Licenciaturas e Fonoaudiologia seria capaz de capacitar o professor a tal ponto. Apropriar-se da Libras, requer, como qualquer outra língua estrangeira, muito mais que um semestre ou um ano todo de curso. Se se fizer uma analogia ao aprendizado da língua inglesa no ensino básico, tem-se praticamente 11 a 12 anos de contato com a língua e dificilmente os alunos saem com esse aprendizado efetivo.

O que a disciplina acaba propondo é uma noção sobre educação de surdos e algumas orientações a respeito de adaptação curricular e avaliativa, estratégias metodológicas, um conhecimento superficial sobre a cultura surda e seus artefatos, além da tentativa de possibilitar

DOI: Em andamento. 
uma conversação simplista em Libras por meio do aprendizado prático de alguns campos semânticos relacionados à identificação, aos cumprimentos, ao ambiente escolar, à família, entre outros necessários à construção sintática, como os verbos e conjunções. Cabe compreender neste aspecto que além das questões gramaticais e estruturais das línguas de sinais, comuns no aprendizado de outras línguas, são necessárias habilidades de expressividade córporo-facial e habilidades motoras, essenciais ao aprendizado da Libras.

O que se observa hoje em dia, em aulas desta disciplina, é uma imensa heterogeneidade no grupo. Algumas aulas são monótonas para uns e extremamente difíceis para outros. Quando se exige maior maleabilidade nos dedos para a execução de algum sinal, uns o fazem com rapidez, destreza e clareza; já outros malmente conseguem deixar a mão na configuração solicitada para a articulação daquele ou desse sinal, considerando apenas os parâmetros linguísticos principais da Libras.

Os conteúdos necessários ao desenvolvimento da disciplina de Libras foram elencados considerando as cinquenta e uma (51) horas da carga horária, para o cumprimento dos objetivos do plano de ensino junto aos acadêmicos do 3o ano do curso de Licenciatura em Matemática turno integral/noturno, durante o segundo semestre de 2013, em uma IES, na cidade de Ponta Grossa. A carga horária total (51h) foi organizada em aulas teóricas (33h) e práticas (18h), deixando evidente os aspectos a serem trabalhados no transcorrer do semestre, tendo como norte a ementa da disciplina, divididos em nove (9) itens.

A organização temática contempla uma abordagem geral sobre os aspectos da educação de surdos nos itens 2, 3 e 7; uma abordagem sociocultural no item 4; uma inserção teórica sobre Libras, quanto ao seu funcionamento linguístico, nos itens 5 e 6; e o conhecimento prático de alguns campos semânticos e seus usos no itens 8 e 9.

Essa ponderação conteudista, permite ao professor da disciplina de Libras trabalhar os principais assuntos que versam sobre a educação de surdos e a Libras, promovendo aos acadêmicos ouvintes do curso de Licenciatura em Matemática um conhecimento global teórico básico, permeado de reflexões sobre a atualidade educacional dos surdos, e de um aprendizado inicial quanto ao uso da comunicação em língua de sinais, no intuito de alcançar o objetivo geral proposto.

Avaliou-se o conhecimento desses acadêmicos por meio de três instrumentos: uma prova escrita, para observação dos conhecimentos teóricos educacionais, linguísticos e legislativos trabalhados; um seminário, sobre os artefatos culturais surdos, na promoção de um envolvimento maior na cultura surda, por meio de leituras e pesquisas midiáticas; e a produção de um curtametragem em expressividade córporo-facial e Libras, como releitura da obra "O Mágico de Oz" (DVD produzido pelos acadêmicos). 
Com o trabalho desenvolvido, buscou-se promover aos acadêmicos competências e habilidades como realçar a expressividade natural do ser humano como parte do processo comunicativo; desenvolver a capacidade comunicativa inicial em uma língua da modalidade visual-gestual; reconhecer a importância do processo histórico mundial dos surdos e dos artefatos culturais surdos como fundamentais para as adaptações didáticas e curriculares destinadas ao ensino do sujeito surdo; compreender o funcionamento linguístico da Libras, em comparação ao funcionamento da Língua Portuguesa; conhecer a legislação vigente sobre a educação dos surdos e as principais concepções educacionais existentes.

\section{A intertenção}

Foi solicitado aos acadêmicos a participação voluntária na pesquisa, para a verificação da contribuição da Libras na formação de professores de Matemática, em ambiente educacional no atendimento de surdos. Apenas uma dos integrantes demonstrou interesse, a qual fez a intervenção em uma turma de EJA - Educação de Jovens e Adultos - constituída de dezessete alunos ouvintes (sendo oito mulheres e nove homens) e três alunos surdos inclusos, no mês de março de 2014. A modalidade de ensino EJA - Educação de Jovens e Adultos - "é destinada àqueles que não tiveram acesso ou continuidade de estudos no ensino fundamental e médio na idade própria" (BRASIL, 2013, LDB 9394/96, art. 37, p. 26).

Foram desenvolvidas quatro (4) aulas junto aos alunos, com a temática "Simetria e Op Art". Para tal proposta, foram realizados quatro encontros para a elaboração da Unidade Didática.

No primeiro encontro, entre a pesquisadora e professor de Artes da EJA, foi determinado o conteúdo matemático a ser abordado durante o assunto Op Art. Foram elencadas as possibilidades de abordagem matemática, mediante a verificação do material sobre Op Art utilizado pelo professor de Artes e também determinado do número de aulas disponibilizadas para essa abordagem. E por fim a determinação de datas para a intervenção, conforme a disponibilidade de aulas da disciplina de Artes em razão da sua carga horária na EJA.

O segundo encontro ocorreu entre a pesquisadora e a acadêmica voluntária, em que foi estudado o material sobre Op Art, para a elaboração do plano de aula, com a abordagem matemática. Foram determinadas quais as atividades práticas possíveis sobre essa abordagem e a Op Art, bem como o estudo e treinamento dos sinais em Libras para o atendimento dos alunos surdos inclusos.

No terceiro encontro, a pesquisadora, o professor de Artes da EJA e a acadêmica de Matemática reuniram-se para a revisão do plano de aula e verificação das atividades práticas propostas. Também foram readequados os slides previamente elaborados para a abordagem matemática na Op Art e determinado o instrumento de avaliação para a disciplina de Artes, bem como os instrumentos de coleta de dados para a pesquisa. 
O quarto encontro foi entre a pesquisadora e a acadêmica, para a elaboração das atividades a serem aplicadas, revisão dos slides para o desenvolvimento da unidade didática, separação do material necessário para a intervenção e treinamento da atuação da acadêmica em Libras e sua filmagem para criação de vídeo sobre Simetria e Op Art.

Coube à acadêmica a execução da Unidade Didática sobre a temática elencada, abordando questões fundamentais da presença e uso do conhecimento matemático nas Artes Visuais. A determinação do conteúdo foi concebida levando-se em consideração o Plano de Ensino da disciplina de Artes, carga horária, e os conteúdos já trabalhados em sala, pertencentes ao Bloco $\mathrm{A}$ desta disciplina. Também foi considerado o material de Op Art utilizado com os alunos, produzido pelo professor, como parte da Unidade Didática, uma vez que essa inserção teve caráter interdisciplinar.

Primeiramente o professor de Artes fez a explicação sobre o assunto Op Art, para posteriormente haver a abordagem da matemática neste segmento. Durante o desenvolvimento do assunto junto aos alunos ouvintes e surdos da EJA foi considerada a diferença linguística dos dois grupos, privilegiando a comunicação com os alunos surdos por meio da Libras sempre que possível pela acadêmica ministrante, comprovando a utilização dos sinais aprendidos por campos semânticos, durante a disciplina de Libras, na graduação.

Não foi descartada a atuação da TILS durante o processo, uma vez que não há o domínio da Libras por parte do professor da disciplina de Arte, necessitando dessa forma a presença dessa profissional. Também porque a competência linguística da acadêmica é limitada a um agrupamento de sinais, não possibilitando uma real explicação.

Em contrapartida, esse conhecimento prévio da acadêmica permitiu que houvesse a interação professor/aluno de maneira mais efetiva, promovendo um contato maior com os alunos surdos e seus aspectos socioculturais. Após explicações e exemplificações, foram propostas três atividades a serem realizadas pelos alunos.

Na Atividade 1, houve a participação dos alunos na análise de aspectos simétricos em obras de Op Art, reproduzidas na TV Pendrive. Na Atividade 2, propôs-se a verificação de reconhecimento do eixo simétrico em uma obra de Op Art apresentada aos alunos por meio de reproduções fotocopiadas, distribuídas a cada um, para posteriormente serem coladas no caderno. Na Atividade 3, houve a distribuição de três folhas, contendo em cada uma imagens em preto e branco de olhos, bocas e mãos respectivamente; e a distribuição, a cada aluno, de uma folha de papel canson cor preta, como base para a criação de uma obra de Op Art com aspecto simétrico. Essa atividade ficou sob a guarda do professor da disciplina de Arte, como requisito parcial de avaliação dos alunos, mas registradas por meio de fotografias. 


\section{Resultados}

Os resultados verificados estão relacionados a diferentes aspectos. Primeiro, as dificuldades associadas ao desenvolvimento da disciplina de Libras junto aos acadêmicos de Licenciatura em Matemática. Em segundo, à intervenção na turma da EJA.

A alocação da disciplina de Libras compõe parte da grade curricular do terceiro ano do curso de Licenciatura em Matemática, mas não tem correlação com nenhuma outra disciplina, provocando um desconforto nos acadêmicos. Diante disso, a abordagem de NEE aos acadêmicos, em um primeiro momento, não é considerada importante para a formação docente, pois argumentam que a capacitação sobre o atendimento aos alunos com necessidades educacionais especiais não é promovido na formação superior e sim na pós-graduação.

As aulas práticas aos acadêmicos foram consideradas de extrema dificuldade, uma vez que o aprendizado da comunicação gestual (em língua de sinais) exige habilidade motora, flexibilidade necessária, memorização, agilidade na sinalização, organização estrutural. $O$ que não é superado em apenas dezoito horas de aula prática. Fator diretamente ligado à carga horária da disciplina, que não é suficiente para o aprendizado de uma língua estrangeira (Libras), em se considerando os conteúdos trabalhados a partir da ementa da disciplina.

Para uma comunicação em sinais é necessário que se desenvolva um autoconhecimento sobre a expressividade corporal como meio comunicacional, para posteriormente se desenvolver o aprendizado dos sinais propriamente dito e em sequência a sua utilização em diferentes contextos. Portanto, as cinquenta e uma horas da disciplina são insuficientes para se abordar todos os conteúdos necessários e promover um aprendizado condizente para o atendimento de alunos surdos inclusos no ensino regular.

Ainda sobre a participação acadêmica, em que nem todos os acadêmicos apresentavam interesse no aprendizado da Libras; por a turma ser pequena (apenas cinco acadêmicos) havia também a dificuldade de participação nas conversações por nem todos estarem presentes. Em razão das faltas, era necessário repetir os sinais trabalhados anteriormente para que todos tivessem o conhecimento necessário (ou pelo menos uma noção) para poder prosseguir com os campos semânticos.

Quanto à Intervenção, inicialmente observou-se que o professor de Artes da EJA não tinha conhecimento da Libras, o que dificultava sua interação com os alunos surdos. Essa responsabilidade foi transferida à TILS - Tradutora e Intérprete de Língua de Sinais - que atende os surdos na sala de aula. Também descobriu-se em conversa que a TILS tem formação acadêmica em Licenciatura em Pedagogia, o que dificultou a interpretação tanto do conteúdo de Artes (Op Art) como do conteúdo matemático (Simetria). Pois em vários momentos, registrados nas filmagens, a intérprete não tinha o domínio dos sinais para uma interpretação adequada e efetiva, 
fazendo uso em diversas situações de recursos expressivos córporo-faciais em substituição dos sinais.

Em relação à acadêmica - ministrante da Unidade Didática, proposta para a intervenção, não houve conhecimento suficiente em Libras para manter uma explicação adequada aos alunos surdos, o que dificultou a interação e explicação com os mesmos. Por se ter mais alunos ouvintes (17) do que surdos (3), a preocupação da acadêmica foi em manter a atenção do grupo, determinando que houvesse muito mais interação oral-auditiva do que visual-gestual.

Evidenciou-se, portanto, que o processo inclusivo de alunos surdos requer uma abordagem bilíngue, um atendimento em que se tenha primeiro o conhecimento em língua de sinais para posteriormente se fazer um correlação com a língua portuguesa na modalidade escrita. $\mathrm{O}$ que se verificou é que não há nenhuma preocupação em se adequar os assuntos em língua de sinais, considerando que a presença da TILS é o suficiente para a efetivação cognitiva dos alunos surdos. Também não houve interação entre alunos ouvintes e surdos, considerando-se inclusão apenas o fato de os surdos poderem compartilhar o mesmo espaço físico que os ouvintes, não havendo a necessidade de comunicação entre eles.

\section{Considerações Finais}

O que se pode considerar como reflexo desse trabalho, desde o desenvolvimento da disciplina de Libras até a intervenção na educação básica, é que a disciplina de Libras não capacita o futuro docente ao atendimento de alunos surdos. Apenas apresenta aspectos culturais, legais, educacionais e linguísticos que promovem aos licenciados uma noção em como se deve trabalhar quando do atendimento ao alunado surdo, sem contar a especificidade de cada área do saber.

Considerar que apenas cinquenta e uma horas são suficientes para a formação adequada dos professores para o atendimento, é ilusão. Ninguém consegue aprender uma segunda língua (estrangeira) em apenas tão pouco tempo, sem ter uma imersão cultural adequada e convívio com pessoas surdas para o aprimoramento linguístico contextualizado.

Considerar que o processo inclusivo de alunos surdos é eficiente, é se enganar. Apenas a presença da TILS, não garante a apropriação do conhecimento abordado nas diferentes disciplinas. Pois deve-se entender que para uma tradução/interpretação adequada o próprio intérprete precisa ter a formação na área em questão, ou ter o acesso aos planos de ensino dos professores para que possa fazer o estudo aprofundado do assunto e pesquisa dos sinais a serem utilizados para determinado fim.

Isso evidencia que as estratégias utilizadas ainda não são suficientes para que a inclusão dos alunos surdos possa garantir a efetivação do aprendizado a essa clientela. Nem mesmo a 
legislação consegue garantir a formação adequada dos licenciados para esse atendimento, em razão dos diversos fatores já citados.

Porém, se se considerar a contribuição dos recursos tecnológicos como facilitadores de conhecimento, há de se garantir uma melhor capacitação dos licenciados e dos docentes que atendem alunos surdos. Em se tratando de um atendimento a distância, há a possibilidade de construção de material digital de qualidade e de acesso gratuito, uma vez que se tenha uma equipe multidisciplinar responsável por atender a demanda de diferentes áreas do saber adaptadas às línguas de sinais.

Portanto, vídeos instrucionais em Libras (como os postados no canal do YouTube), bem como a criação de um ambiente apropriado para esse tipo de atendimento (blog educacional) poderão garantir uma melhor atuação profissional dos educadores e uma efetivação do conhecimento aos alunos surdos, que também podem ter acesso a esse mundo, interagindo em sua própria língua. Não é o fim dos problemas da educação de surdos, mas uma solução mais eficaz em que se respeita a diferença linguístico-cultural desses alunos, garantindo uma equiparação de direitos do cidadão.

\section{Referências}

ALMEIDA, J. F. de.; VITALIANO, C. R. A disciplina de libras na formação inicial de pedagogos:

experiência dos graduandos. IN: IX ANPED SUL - Seminário de Pesquisa em Educação da Região Sul. Londrina, 2012. Disponível em:

http://www.ucs.br/etc/conferencias/index.php/anpedsul/9anpedsul/paper/viewFile/2429/582 Acesso em: fev/2013.

BRASIL. LDB 9394/96. Lei de Diretrizes e Bases da Educação Nacional. N. 9394 de 20 de dezembro de 1996. Disponível em: http://www.planalto.gov.br/ccivil_03/leis/19394.htm

IFRAH, G. História universal dos algarismos: a inteligência dos homens contada pelos números e pelo cálculo. Rio de Janeiro: Nova Fronteira, 1997. v.1.

LOPES, E. Fundamentos da linguística contemporânea. São Paulo: Cultrix, 2007.

MARTINEZ, P. Didáticas de línguas estrangeiras. São Paulo: Parábola, 2009.

MORAES, M.C.; PESCE, L.; BRUNO, A. R. (org.) Pesquisando fundamentos para novas práticas na educação online. São Paulo: RG, 2008.

SANTANA, A. P. Surdez e linguagem: aspectos e implicações neurolinguísticas. São Paulo: Plexus, 2007.

SANTOS, C. F. R. dos et al. Educação matemática: dimensões teórico-metodológicas 2. Ponta Grossa-PR: UEPG/NUTEAD, 2010.

R. B. E. C. T., vol 8, Ed. Sinect, jan-abr.2015 ISSN - 1982-873X

DOI: Em andamento. 
SAUSURRE, F. de. Curso de Linguística Geral. São Paulo: Cultrix, 1995.

SILVA, R. C. da. Libras - Língua Brasileira de Sinais - uma possibilidade de segunda língua para ouvintes. IN: Anais - EDUCERE - IX Congresso Nacional de Educação/ III Encontro Sul Brasileiro de Psicopedagogia. Curitiba: PUCPR, 26 a 29 de outubro de 2009. (p. 2521-2534) Disponível em: http://www.pucpr.br/eventos/educere/educere2009/anais/pdf/1883_1307.pdf

SLOMSKI, V. G. Educação bilíngue para surdos: concepções e implicações práticas. Curitiba: Juruá, 2011.

STUMPF, M. R. Introdução e Minhas Palavras. In: SUTTON, V. Um sistema de escrita para língua de sinais. Porto Alegre: PUCRS/ULBRA, s/d. Tradução: Marianne Rossi Stumpf. Projeto SignNet, CNPq/ProTeM - UCPel/PUCRS/ULBRA Disponível em:

http://www.signwriting.org/archive/docs5/sw0472-BR-Licoes-SignWriting.pdf Acesso em: $13 / 02 / 2014$.

SUTTON, V. SignWriting: sign languages are written languages! USA: The Signwriting Press, 2009. Disponível em:

http://www.signwriting.org/archive/docs9/sw0821_SignWriting_Basics_Instruction_Manual_Sutt on.pdf

TAVARES, I. M. S.; CARVALHO, T. S. S. de. Inclusão escolar e a formação de professores para o ensino de Libras (língua Brasileira de Sinais): do texto oficial ao contexto. IN: Anais - V EPEAL Pesquisa em Educação: Desenvolvimento, ética e responsabilidade social. Maceió: UFAL, 2010. (p. 1-15) Disponível em: http://dmd2.webfactional.com/anais/

Rúbia Carla da Silva - Mestre em Ensino de Ciência e Tecnologia pela Universidade Tecnológica Federal do Paraná - UTFPR - PPGECT. Especialista em Educação Especial, pela Universidade Estadual de Ponta Grossa - UEPG. Especialista em Língua Portuguesa: ensino e prática, pelas Faculdades Integradas do Vale do Ivaí - UNIVALE - ESAP. Professora de Libras na Universidade Estadual de Ponta Grossa - UEPG, pelo Departamento de Estudos da Linguagem - DEEL. Coordenadora do Curso de Letras - Português e Libras, pela Faculdade Sant'Ana. Intérprete e Tradutora de Língua de Sinais - TILS, pela SEED-PR/FENEIS. letraslibras@iessa.edu.br

Eloiza Aparecida Ávila de Matos - Doutora em Educação pela Universidade Metodista de Piracicaba - UNIMEP. Estágio doutoral na Université de Technologie de Compiègne França Centre d Innovation Tecnologique. Mestre em Tecnologia Universidade Tecnológica Federal do Paraná- PPGTE. Professora da Universidade Tecnológica Federal do Paraná - UTFPR - Campus de Ponta Grossa no Programa de Pós Graduação em Ensino de Ciência e Tecnologia - PPGECT - 
Mestrado e Doutorado. Professora pesquisadora do Programa de Pós Graduação em Engenharia de Produção - UTFPR - PPGEP. elomatos@utfpr.edu.br 